\title{
Design Implications of Model-Generated Urban Data
}

\author{
Ljubomir Jankovic
}

\begin{abstract}
The staggering complexity of urban environment and long timescales in the causal mechanisms prevent designers to fully understand the implications of their design interventions. In order to investigate these causal mechanisms and provide measurable trends, a model that partially replicates urban complexity has been developed. Using a cellular automata approach to model land use types and markets for products, services, labour and property, the model has enabled numerical experiments to be carried out. The results revealed causal mechanisms and performance metrics obtained in a much shorter timescale than the real-life processes, pointing to a number of design implications for urban environments.
\end{abstract}

Keywords: Urban modelling, cellular automata, market mechanisms, urban performance metrics, urban design implications

\subsection{Introduction}

The urban environment consists of a number of parts such as different land use types, with buildings and people in them. These different parts interact in many different ways with each other through exchange of materials, resources, economic activity and data, giving rise to immense complexity of the system. Whilst it is not easy to model such complexity, the challenges of climate change, increasing population and diminishing resources make it imperative to create models that can depict urban complexity and provide designers with tools for informed decision making. This article introduces a model that goes some way towards replicating urban complexity, through developing a cellular approach to modelling land use types, providing the cells with own individual 'metabolism', and linking such metabolism into models of market economics. The model is governed by the principles of emergence, where the interaction between the constituent parts based on simple rules gives rise to complex behaviour of the model.

The cellular approach to modelling is not new. In 1940s, John von Neumann worked on models of selfreproducing machines (von Neumann, 1951) but was unable to formulate a fully self-reproduceable machine until a colleague mathematician Stanislav Ulam suggested him to use a cell-based concept. Thus, cellular automata machines were formulated and developed as result of biological inspiration (von Neumann, 1967). Wolfram (2002) worked extensively on cellular automata machines and developed simple rules that resemble various complex structures in nature, such as shell shapes and animal pigmentation patterns. A significant outcome of Wolfram's seminal

Stable URL: https://arcc-journal.org/index.php/arccjournal/article/view/1061 10.17831/enq:arcc.v16i1.1061

Corresponding Author: L.Jankovic@herts.ac.uk

Published by the Architectural Research Centers Consortium under the terms of the Attribution-NonCommercial-ShareAlike 4.0 International license 
work published in a book entitled 'A new kind of science' (Wolfram, 2002) is the Principle of Computational Equivalence. According to this principle, "all processes, whether they are produced by human effort or occur spontaneously in nature, can be viewed as computations" (Wolfram 2002, p. 715). According to Wolfram, the essence of the Principle of Computational Equivalence is that "no system can ever carry out explicit computations that are more sophisticated than those carried out by systems like cellular automata and Turing machines". As cellular automata machines and Turing machines are based on simple rules on a component level that give rise to complex behaviour of the systems they are modelling, it follows that urban development can also be expressed with simple rules on a component level that give rise to complex behaviour. Batty (2007) investigated various ways of applying cellular automata to urban modelling. He investigated how cellular models give rise to self-organised criticality, where the models are consistently poised at the phase transition between order and chaos. His work led to the investigation of fractal properties of urban grain, and of similarities with other non-urban phenomena, including forest fire models (Koutitas, Pavlidou, and Jankovic 2010). Complexity of urban models, which is defined as transition phase between order and chaos (Langton, 1992), can be measured, using either Shannon Entropy (Shannon, 1948) or Langton's $\lambda$ (Langton, 1989). Whilst these measures are useful for researchers, they are of little use for design practitioners.

This article is written in an attempt to bridge the gap between theoretical research in urban modelling and the practice of urban planning, and will focus on design implications of model-generated urban data, guided by the following research questions:

What kind of urban data can be generated by a functional model?

What could be the design implications of such data?

As urban modelling is now over 50 -years old since the publication of Statistical Theory of Spatial Distribution Models (Wilson A. G., 1967), Wilson A. (2018) argues that in addition to a significant scope for a continuing theoretical research, the interdisciplinary characteristics of urban models give scope for practical applications in planning, and this article aims to facilitate that objective.
Like many urban models available today, the model introduced in this article is based on cellular automata. However, unlike the urban models available today, it combines cell 'metabolism' with market economics, whilst combining its inputs with population, energy and planning data obtained from several local authorities in Europe as part of a funded project. Combining all inputs and algorithms into a unified urban process, it provides a range of metrices that enable evaluation of the model performance throughout the simulation time.

Although the experiments presented in this article are based on randomly generated urban structures, the practical value of the method is not diminished. The underlying tool in which the model resides enables geographic data to be imported and mapped to the model structures, so that model calibration can be carried out, thus giving urban designers tools that can be used for investigating future effects of urban design interventions.

\subsection{Method}

In preparation for the development of the method, it became apparent that fully programmable control of the modelling development was required. Collaboration between different organisations running different computer platforms required a cross-platform application program interface and a cross-platform graphical user interface. This, together with the relevant programming expertise of the project investigators, was the reason for choosing Java programming language for the implementation of the method. The platform for the resultant City Analysis Simulation Tool is therefore entirely bespoke, developed in Java programming language for the purpose of implementing this method.

Another decision that had to be made was the choice between vector and raster data types used in mapping the urban environment. Whilst vector data are based on formulae and therefore infinitely scalable, this type of data could not be easily represented as a part of a complex system interacting with the neighbouring entities. Adopting raster data approach, comprised of individual blocks, provided the opportunity for neighbour to neighbour interaction that is fundamental for the behaviour of complex systems. That dictated the choice of cellular automata as a suitable representation of the raster data type, where each cell will be assigned a land use type and a type of interaction with the neighbouring 
cells. As a land use cell interacts with the surrounding neighbourhood of eight cells (also called Moore neighbourhood in cellular automata terminology), it changes its state while going from time to time $t+1$ on the basis of its metabolism, as illustrated in Figure 1 , where each step corresponds to a year of the real time. Connections outside of the immediate neighbourhood were subsequently achieved using the market modules, where supply and demand actions effectively created connections between distant cells on the grid.

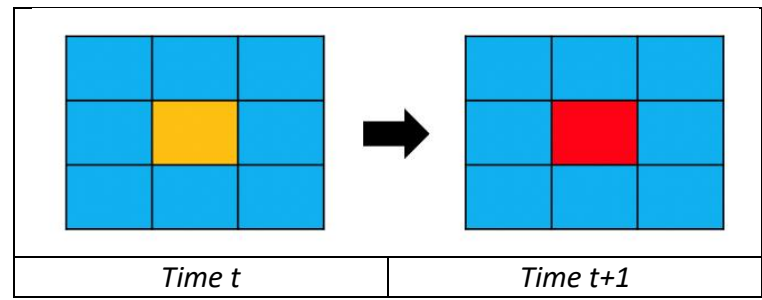

Figure 1: Land use cell (centre) changing from time t to $t+1$ through interaction with surrounding cells

Development and implementation of every new step of the method was a separate challenge that had to be resolved, including: definition and specification and the total number of the land use cell types; metabolism in each cell type; connectivity between different cell types; development of self-regulated market models where supply and demand regulate the price; importing GIS data into the model; and dealing with increasing data input types into the model without making the model deterministic, thus keeping its emergent properties.

Thus, the urban model introduced in this article is based on different land use types represented as rectangular cells using a cellular automata framework. There are 23 cell types in the model, as detailed out in Table 1. Each of these cell types have individual processes in them, as well as the cells link to four different markets: products, services, labour and property markets. All cell types are categorised according to their economic activity as follows:

- Production

- Service

- Transport

- Home

- Neutral

A taxation system is introduced in the model, consisting of the following resource accumulators called 'boxes' as follows:

- Tax Box

- Building maintenance box

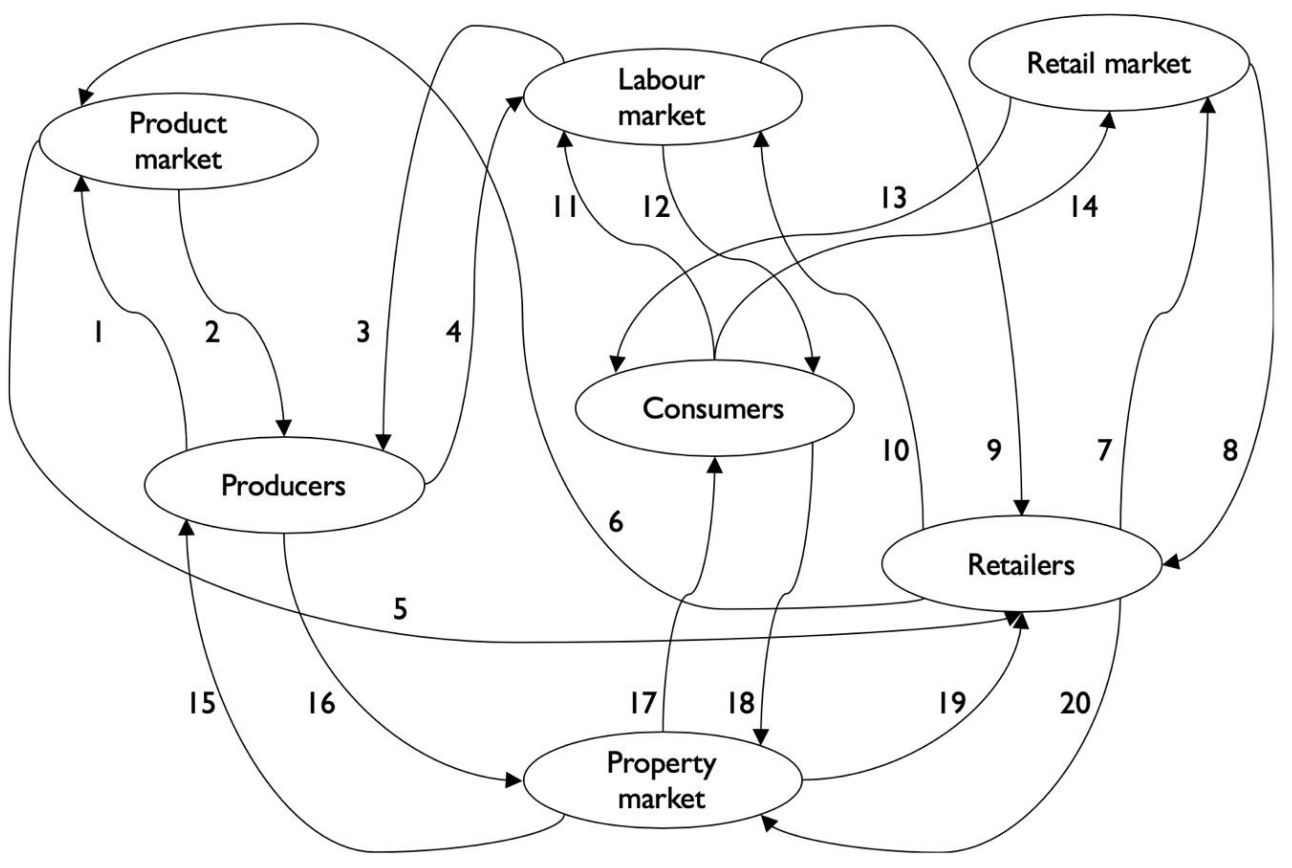

Figure 2: Processes between cells and markets 
- Energy box

- Rent box

- Quality of public space box

- Transport box

Depending on the type and economic activity, each cell interacts with the four different markets, as shown in Figure 2 and pays tax into appropriate expenditure 'boxes', as shown in Table 1.
Why should brownfield and water be considered to be economically neutral? In this model brownfield and water do not have "metabolism" that interacts with other land use types. Whilst in real life that may not be so, in this model this was chosen as a simplification.

The processes between the cells and the markets are described as follows, with reference to Figure 2:

\begin{tabular}{|c|c|c|c|}
\hline $\begin{array}{l}\text { Cell type } \\
\text { number }\end{array}$ & Cell type & Income & Expenditure \\
\hline \multicolumn{4}{|l|}{ Production } \\
\hline 2 & Industry & From employees' work & Into all boxes \\
\hline 10 & Agriculture & From employees' work & Into all boxes \\
\hline 6 & Office & From employees' work & Into all boxes \\
\hline \multicolumn{4}{|l|}{ Service } \\
\hline 3 & Retail & From residential cells expenditure & $\begin{array}{l}\text { Into producers plus into all six } \\
\text { boxes }\end{array}$ \\
\hline 7 & Warehouse & From industry & $\begin{array}{l}\text { Into residential plus into all six } \\
\text { boxes }\end{array}$ \\
\hline 8 & Urban Green Space & From QualityOfPublicSpaceBox & Into EnergyBox \\
\hline 12 & Built heritage & From TaxBox & $\begin{array}{l}\text { Into EnergyBox and } \\
\text { BuildingMaintenance box }\end{array}$ \\
\hline 13 & Health & From producers, or tax, or both & Into retailers plus into all six boxes \\
\hline 14 & Education & From residential cells & $\begin{array}{l}\text { Into producers plus into all six } \\
\text { boxes }\end{array}$ \\
\hline 15 & Public Access Buildings & From TaxBox & $\begin{array}{l}\text { Into EneryBox and } \\
\text { BuildingMaintenance box }\end{array}$ \\
\hline 16 & Military \& Prison & From TaxBox & $\begin{array}{l}\text { Into EneryBox and } \\
\text { BuildingMaintenance box }\end{array}$ \\
\hline 17 & Public Square & From QualityOfPublicSpaceBox & Into EnergyBox \\
\hline 22 & Leisure & From residential cells & $\begin{array}{l}\text { Into producers plus into all six } \\
\text { boxes }\end{array}$ \\
\hline \multicolumn{4}{|l|}{ Transport } \\
\hline 1 & Roads & From TravelBox & $\begin{array}{l}\text { Into EnergyBox and } \\
\text { BuildingMaintenance box }\end{array}$ \\
\hline 11 & Rail \& Metro & From TravelBox & $\begin{array}{l}\text { Into EnergyBox and } \\
\text { BuildingMaintenance box }\end{array}$ \\
\hline 18 & Transport Interchange & From TravelBox & $\begin{array}{l}\text { Into EnergyBox and } \\
\text { BuildingMaintenance box }\end{array}$ \\
\hline 21 & Car park & From TravelBox & $\begin{array}{l}\text { Into EnergyBox and } \\
\text { BuildingMaintenance box }\end{array}$ \\
\hline \multicolumn{4}{|l|}{ Home } \\
\hline 4 & Residential & From salaries at producers or from tax & Into retailers plus into all six boxes \\
\hline \multicolumn{4}{|c|}{ Economically Neutral } \\
\hline 0 & Brownfield & N/A & N/A \\
\hline 5 & Water & N/A & N/A \\
\hline 9 & Non-agricultural vegetation & N/A & N/A \\
\hline 19 & Other & N/A & N/A \\
\hline 20 & Boundary & N/A & N/A \\
\hline
\end{tabular}

Table 1: Model land use cell types grouped into economic categories 
1. Producers make products and send them to the product market

2. Producers draw income from the product market price regulated by supply and demand in the product market

3. Producers obtain labour from the labour market

4. Producers pay for the labour based on the labour market price regulated by supply and demand in the labour market

5. Retailers purchase products from the product market

6. Retailers pay the market price for the products regulated by supply and demand in the product market

7. Retailers send products to the retail market

8. Retailers draw income from the retail market price regulated by supply and demand in the retail market

9. Retailers obtain labour from the labour market

10. Retailers pay for the labour based on the labour market price regulated by supply and demand in the labour market

11. Consumers supply labour to the labour market

12. Consumers draw income from the labour market price regulated by supply and demand in the labour market

13. Consumers purchase goods from the retail market

14. Consumers pay for the goods based on the retail market price regulated by supply and demand in the retail market

15. Producers obtain property from the property market

16. Producers pay for the property based on the property market price regulated by supply and demand in the property market

17. Consumers obtain property from the property market

18. Consumers pay for the property based on the property market price regulated by supply and demand in the property market

19. Retailers obtain property from the property market

20. Retailers pay for the property based on the property market price regulated by supply and demand in the property market.

The market price in all four markets is regulated on the basis of supply and demand as follows:
- If supply is greater than demand, then new price $=0.95 \times$ old price

- If supply is less than demand, then new price $=1.05 \mathrm{x}$ old price

- If supply is equal to demand, then new price = old price

Recursive use of the above rules in each timestep cause price fluctuations over time that are much greater than the fluctuations in individual timesteps.

The balance between income and expenditure in each cell is accumulated in each step into cell 'fitness'. Thus, each cell has its own 'fitness' balance denoted as follows:

fitness $=$ income - expenditure - running costs

Economic output is converted into jobs in production and service cells or into inward migration in residential cells. In addition to inward migration, the population of residential cells is influenced by the birth rate and death rate set in the model (Table 2 ). If the number of jobs in a production or service cell or the number of people in a residential cell increases above a certain density threshold set in the model, the cell will seek to expand and will look out radially for an unoccupied cell. Alternatively, if the number of jobs or the number of people in the respective cells falls to zero, the cell becomes unoccupied and can be taken over by other expanding cells.

Each cell is assigned energy consumption and carbon emissions according to its type. These were obtained in consultation with energy professionals and built into the model on the basis of data in Table 3.

In searching for a suitable location to expand into, the cells conduct 'radar' type of radial search in a circle around them within a specified horizon. Each cell type is assigned a certain 'attractiveness' value between 0 and 1 . Thus roads have attractiveness of 1 , and brownfield sites attractiveness of 0 and other cells have their attractiveness proportional to their fitness and proximity to the centre of urban activity. While looking for a location to expand into, the cells will take a preference of higher attractiveness of the vacant location. If no vacant location is found, then the expanding cell will take over an occupied cell with a lower fitness.

The cell types are initialised either manually by using the model's drawing function, or are randomly generated, or are imported from a GIS file. In addition 
to expansion of cells into the cells of the same type depending on jobs or people, the cell types can change through random 'mutation' into another cell type, based on the built-in planning rules shown in Table 4. First, a cell for mutation is selected randomly from the rectangular grid of cells (for instance $100 x$ 100) and subsequently the cell is converted into another cell type based on a relevant planning rule. The planning rules have been obtained from discussions with local authorities across Europe and include the population basis for a certain type of cell to be created. For instance, a primary care health centre is created for population of N1 inhabitants, a primary school is created for a population of N2 inhabitants and so on, based on an extensive table coded in the model. Cells can also be protected, such as roads, so that they are not subjected to expansion takeover or mutation from other cell types.

\begin{tabular}{|c|c|}
\hline Description & Value \\
\hline Income per capita & 20000 \\
\hline Population per $10000 \mathrm{~m}^{2}$ & 100 \\
\hline \multicolumn{2}{|l|}{ Births and deaths } \\
\hline Birth rate[\%] & 1.123 \\
\hline Death rate[\%] & 1.018 \\
\hline \multicolumn{2}{|l|}{ Age profile } \\
\hline Total[\%] & 100 \\
\hline Preschool[\%] & 15 \\
\hline School[\%] & 15 \\
\hline University[\%] & 15 \\
\hline Working[\%] & 45 \\
\hline Retired[\%] & 10 \\
\hline \multicolumn{2}{|l|}{ Household profile } \\
\hline Total[\%] & 100 \\
\hline One Person[\%] & 13 \\
\hline Couple no children[\%] & 25 \\
\hline Couple with Children[\%] & 46 \\
\hline Lone Parent with Children[\%] & 10 \\
\hline Other[\%] & 5 \\
\hline
\end{tabular}

\begin{tabular}{|c|c|}
\hline Description & Value \\
\hline \multicolumn{2}{|l|}{ Household Expenditure } \\
\hline Total Expenditure[\%] & 100 \\
\hline Food and non-alcoholic beverages[\%] & 18.7 \\
\hline Alcoholic beverages and tobacco[\%] & 2.8 \\
\hline Clothing and footwear[\%] & 19.8 \\
\hline $\begin{array}{l}\text { Housing + water + electricity+ gas and other } \\
\text { fuels[\%] }\end{array}$ & 6.6 \\
\hline $\begin{array}{l}\text { Furnishings }+ \text { household equipment and } \\
\text { routine maintenance[\%] }\end{array}$ & 7.2 \\
\hline Health[\%] & 5.2 \\
\hline Transport[\%] & 15 \\
\hline Communication[\%] & 3.3 \\
\hline Recreation and culture[\%] & 4.8 \\
\hline Education[\%] & 1.3 \\
\hline Restaurants and hotels[\%] & 9.5 \\
\hline Miscellaneous goods and services[\%] & 6.1 \\
\hline \multicolumn{2}{|l|}{ Household Income } \\
\hline Total net income[\%] & 100 \\
\hline Income from employment[\%] & 49.6 \\
\hline Income from self employment[\%] & 9.8 \\
\hline Pensions and social security[\%] & 19.4 \\
\hline
\end{tabular}

Table 2: Population data

The figures shown in Table 2 arise from a collaboration with local authorities and an energy agency in Portugal and correspond to their statistics. This explains the lower energy consumption figures than those expected in northern countries, however this type of data is fully editable and can be amended for different local conditions. In the first iteration of this work the population was not modelled to account for behavioural differences between social groups, but this is something that can be added in the future.

The overall result is that model is entirely based on principles of emergence, where local rules on a component level, through component to component interaction give rise to complex behaviour (Jankovic, 2012). 


\begin{tabular}{|c|c|c|}
\hline Cell type & $\begin{array}{l}\text { Energy } \\
\text { consumption } \\
\mathrm{TJ} /\left(\mathrm{m}^{2} \text {.year }\right)\end{array}$ & $\begin{array}{l}\mathrm{CO}_{2} \text { emissions } \\
\text { (tonnes/ } \\
\left(\mathrm{m}^{2} \text {.year)) }\right.\end{array}$ \\
\hline $0=$ Brownfield & 0.000000 & 0.000000 \\
\hline $1=$ Roads & 0.002895 & 0.400000 \\
\hline $2=$ Industry & 0.003619 & 0.500000 \\
\hline 3=Retail & 0.002109 & 0.291330 \\
\hline 4=Residential & 0.000317 & 0.041164 \\
\hline $5=$ Water & 0.000000 & 0.000000 \\
\hline 6=Office & 0.000840 & 0.115669 \\
\hline 7=Warehouse & 0.000671 & 0.091836 \\
\hline $\begin{array}{l}\text { 8=Urban Green } \\
\text { Space }\end{array}$ & 0.000000 & 0.000000 \\
\hline $\begin{array}{l}\text { 9=Non-Agriculture } \\
\text { Vegetation }\end{array}$ & 0.000000 & 0.000000 \\
\hline 10=Agriculture & 0.002895 & 0.400000 \\
\hline 11=Rail \& Metro & 0.002895 & 0.400000 \\
\hline 12=Built heritage & 0.000145 & 0.015088 \\
\hline 13=Health & 0.000839 & 0.090436 \\
\hline 14=Education & 0.000317 & 0.041164 \\
\hline $\begin{array}{l}\text { 15=Public Access } \\
\text { Buildings }\end{array}$ & 0.000346 & 0.032961 \\
\hline 16=Military \& Prison & 0.000419 & 0.039744 \\
\hline 17=Public Square & 0.000145 & 0.015088 \\
\hline $\begin{array}{l}\text { 18=Transport } \\
\text { Interchange }\end{array}$ & 0.002895 & 0.400000 \\
\hline 19=Other & 0.000000 & 0.000000 \\
\hline 20=Boundary & 0.000000 & 0.000000 \\
\hline 21=Car park & 0.000724 & 0.100000 \\
\hline 22=Leisure & 0.001566 & 0.192785 \\
\hline
\end{tabular}

\begin{tabular}{|c|c|}
\hline Facilities & $\begin{array}{l}\text { Population } \\
\text { basis }\end{array}$ \\
\hline \multicolumn{2}{|l|}{ Education } \\
\hline Nursery & 5000 \\
\hline Pre-primary & 900 \\
\hline Primary & 2000 \\
\hline Lower secondary & 3800 \\
\hline Upper secondary & 13000 \\
\hline University & 200000 \\
\hline Professional education & 50000 \\
\hline \multicolumn{2}{|l|}{ Health } \\
\hline Specialist - national & 3000000 \\
\hline Specialist - regional & 200000 \\
\hline Local - primary care & 4000 \\
\hline \multicolumn{2}{|l|}{ Emergency services } \\
\hline Police & 10000 \\
\hline Fire & 40000 \\
\hline Ambulance & 10000 \\
\hline \multicolumn{2}{|l|}{ Publicly funded facilities } \\
\hline Public access buildings & 10000 \\
\hline Public square & 20000 \\
\hline Military \& prison & 200000 \\
\hline Urban green space & 200000 \\
\hline \multicolumn{2}{|l|}{ Leisure } \\
\hline Basic sports centre & 800 \\
\hline Leisure centre & 10000 \\
\hline Open space (100 x 100 metres) & 10000 \\
\hline Water (100 x 100 metres) & 20000 \\
\hline \multicolumn{2}{|l|}{ Retail \& distribution } \\
\hline Local shop & 10000 \\
\hline Shopping centre & 100000 \\
\hline Warehouse & 100000 \\
\hline \multicolumn{2}{|c|}{ Primary production \& commercial services } \\
\hline Industry & 0 \\
\hline Agriculture & 0 \\
\hline Office space & 0 \\
\hline
\end{tabular}

Table 4: Planning data 


\subsection{Experiments and results}

A number of experimental runs carried out with the model are introduced in this section. Figure 3 shows a simulation of urban expansion over a period of 25 timesteps, corresponding to 25 years. In Figure 3, row a), position a1, an initial set of land cells was initialised randomly, and two roads shown in black were drawn manually. As the simulation progresses, the land use cells follow the roads while expanding (positions a2a4). The road following is an emergent property of the model that was not explicitly programmed. It is a consequence of the roads having attractiveness of $A$ $=1$, and diffusing that attractiveness outwards, as shown in Figure 3, row b). As the expanding land use cells have a preference towards expanding into vacant cells with higher attractiveness, that has an unintended consequence of road following. In step 23, Figure 3 , position a4, a large retail area was entered manually shown above the region where the roads cross. This resulted in a disruption of the fine grain urban environment, which will be discussed later in this article. Figure 3, row b) therefore shows the changing and outwardly diffusing attractiveness from the road cells, whilst small white areas around the crossroads show the established cells with repellent quality, so that they cannot be taken over by other cells. Finally, Figure 3, row c) shows carbon emissions from the land use cells, resulting from the application of energy and $\mathrm{CO}_{2}$ emissions factors from Table 3.

The final step of the simulation of urban expansion is shown in Figure 4.

Throughout the simulation, occasional mutation of cell types was occurring according to the planning rules data from Table 4.

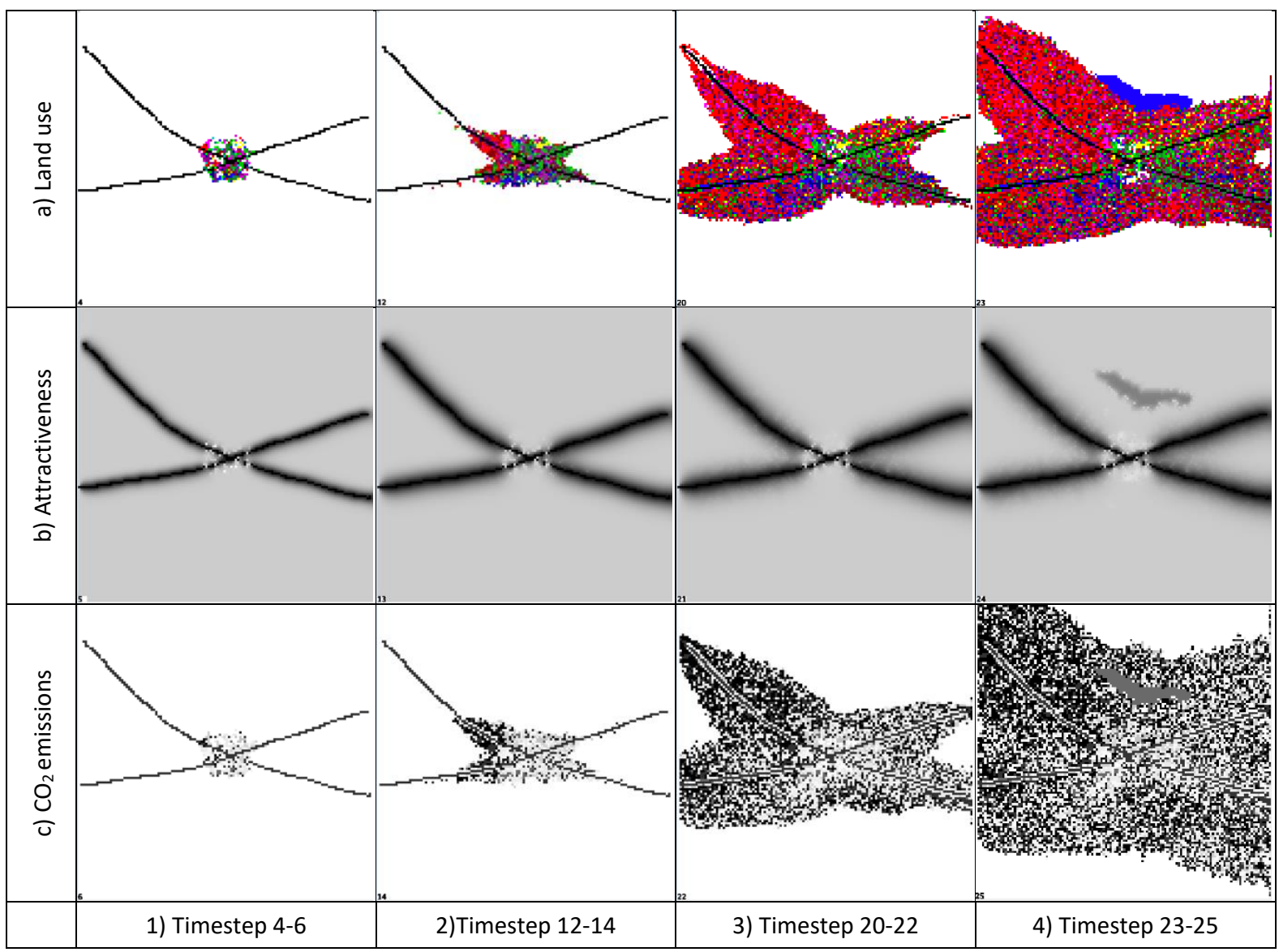

Figure 3: Simulation of urban expansion 


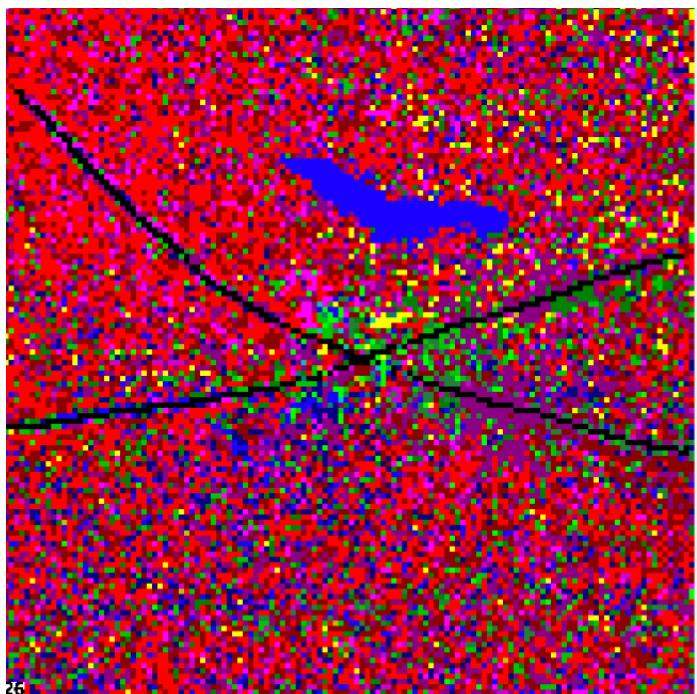

Figure 4: The final step of the simulation of urban expansion

At every step of the process the clusters of land use types can be analysed. A cluster is defined as a collection of the cells of the same type that are placed next to each other. A frequency of occurrence of cluster sizes is analysed for the final step of the simulation and shown in Figure 5, at the time when the number of occupied cells reached 9040 and the number clusters reached 3635 . It is possible to observe from the normal plot of the frequency of occurrence of clusters in Figure 5 a that small clusters occur frequently, and large clusters occur infrequently. This is a signature of the power law distribution in the form of

$$
y=c x^{-a}
$$

where ' $c$ ' and ' $a$ ' are constants. The normal plot in this particular case is not easy to interpret, as a number of features are lost in the scaling of the plot between cluster sizes of 0 and 50 . This is where a log-log plot of the cluster size frequency, shown in Figure $5 b$, becomes useful. As it can be seen from the log-log plot, there is some irregularity between cluster size logarithms of 3 to 3.5. This is likely to be the result of the 'artificial' introduction of the large retail cluster in Figure 3, position a4, and it could possibly have a knock on effect on the future urban development in that area, as more intensive processes in and out of such a large cluster may result in the changes of the urban fabric around it, and the cells changing their type as result.

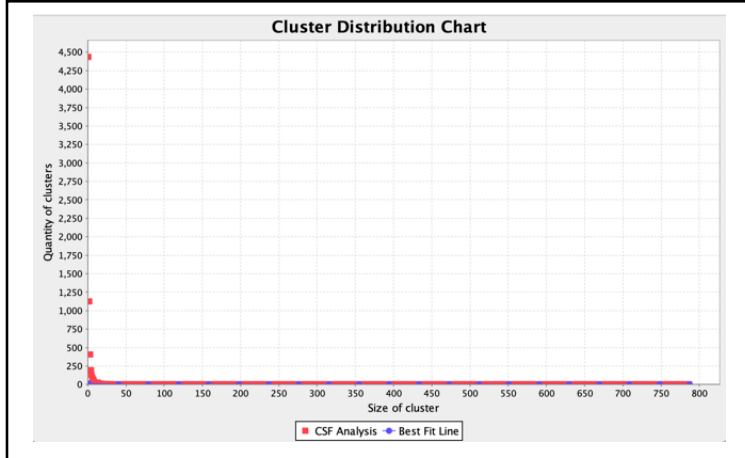

a) Normal plot

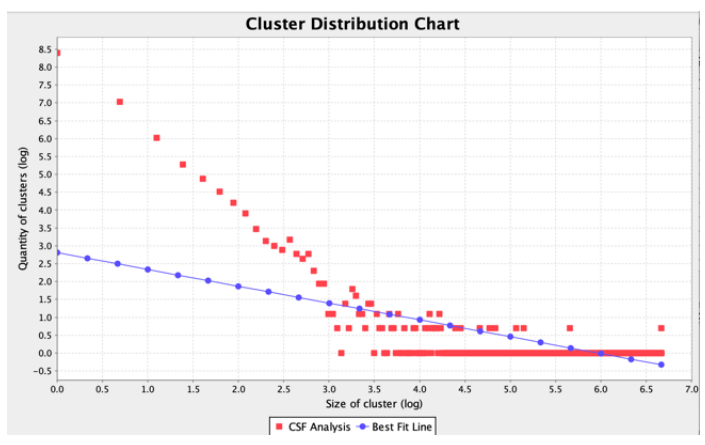

b) Log-log plot

Figure 5: Cluster size frequency distribution: 9040 cells, 3635 clusters

Other types of output that can be obtained from the cellular model are population changes over a period of time (Figure 6a), and market price indices for the product market (Figure $6 \mathrm{~b}$ ), service/retail market (Figure 6c), and labour market (Figure 6d). The population graph shows linear growth with time from year 1 to 2, exponential growth from year 2 to around year 14, a linear decline from years 14 to 15 , and then even more rapid exponential growth until the end of the simulation. As it can be seen from Figure $6 \mathrm{~b}$ and $c$, the product and service market indices decline rapidly, then go through a steady rise and start fluctuation towards the end of the simulation, as result of the urban expansion and changes of the proportion of the urban cell types and consequent balances of supply and demand. The labour market price index graph, Figure $6 \mathrm{~d}$, shows initially slow growth, followed by a rapid exponential growth towards the end of the simulation. 


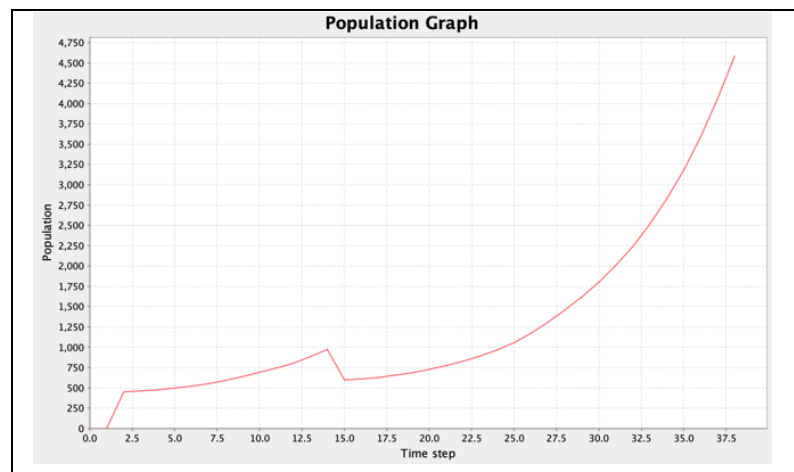

a) Population graph

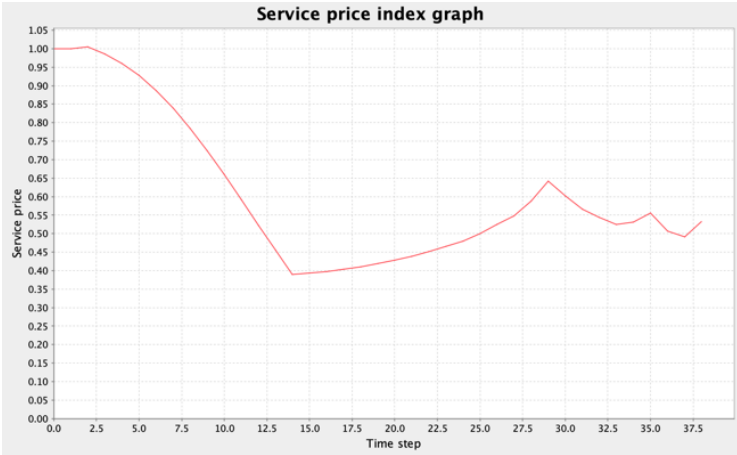

c) Service price index graph

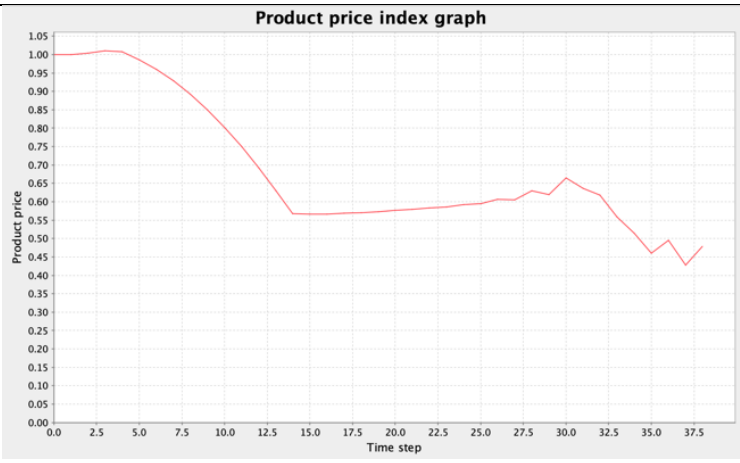

b) Product price index graph Labour price index graph

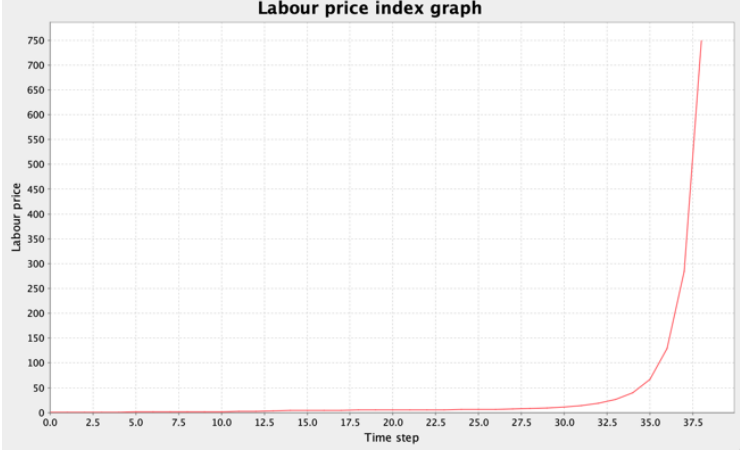

d) Labour price index graph

Figure 6: Population metrics and market indices

Energy consumption and carbon emissions graphs were obtained at step 25 of the simulation (Figure 7). Both have a similar increasing trend, but at different respective scales resulting from the energy consumption and carbon emissions figures based on data from Table 3.

The model enables the cell types to be summarised at different stages of the simulation, as shown in Figure 8. That gives an additional context to the other metrics obtained from the model, for instance the changes and fluctuation of market indices.

Another useful feature of the cellular automata model is the ability to spontaneously grow secondary roads on the basis of simple local rules in each cell. If a cell has lower attractiveness than the neighbouring cells and higher density, a secondary road will be grown through the cell in the direction of increasing attractiveness gradient. As main roads have attractiveness of $A=1$ and as attractiveness diffuses

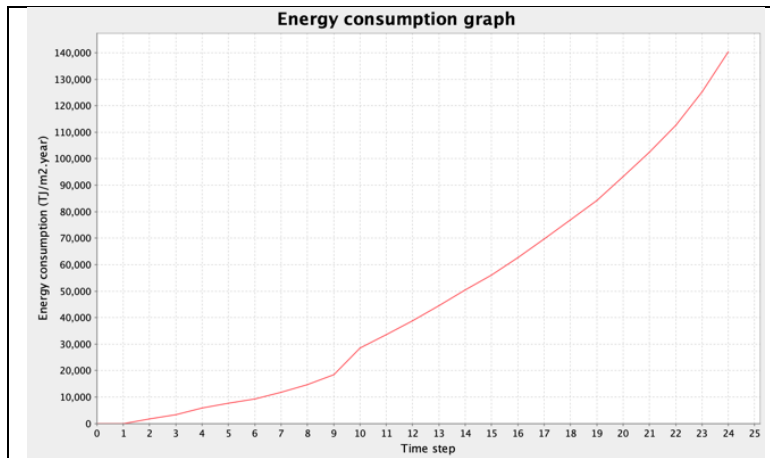

a) Energy consumption

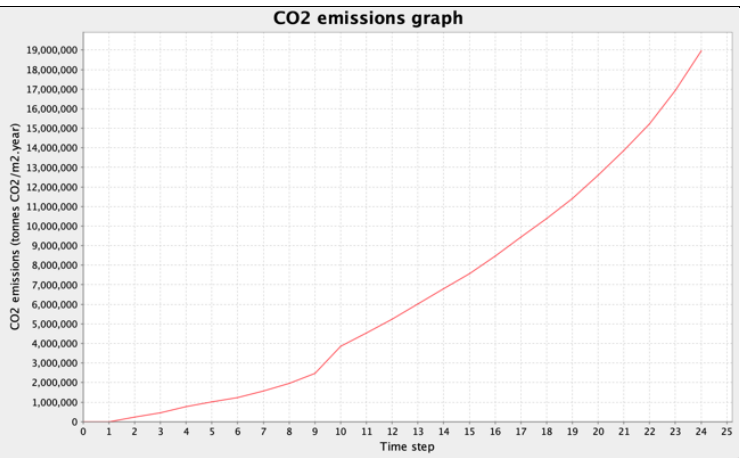

b) Carbon emissions

Figure 7: Energy consumption carbon emissions 


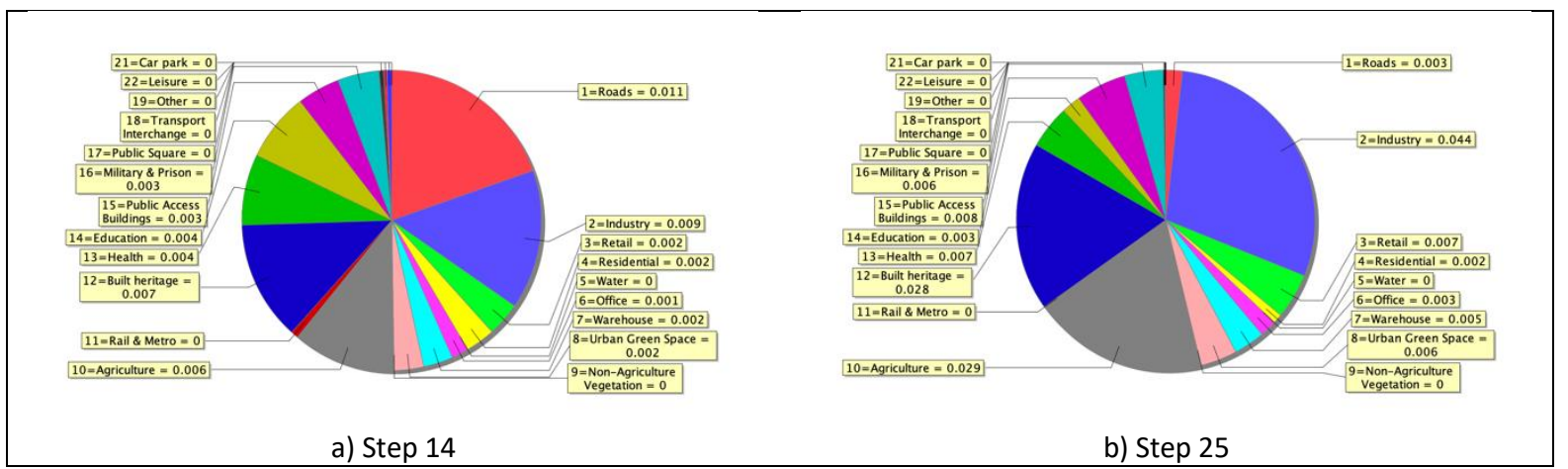

Figure 8: Proportion of cell types

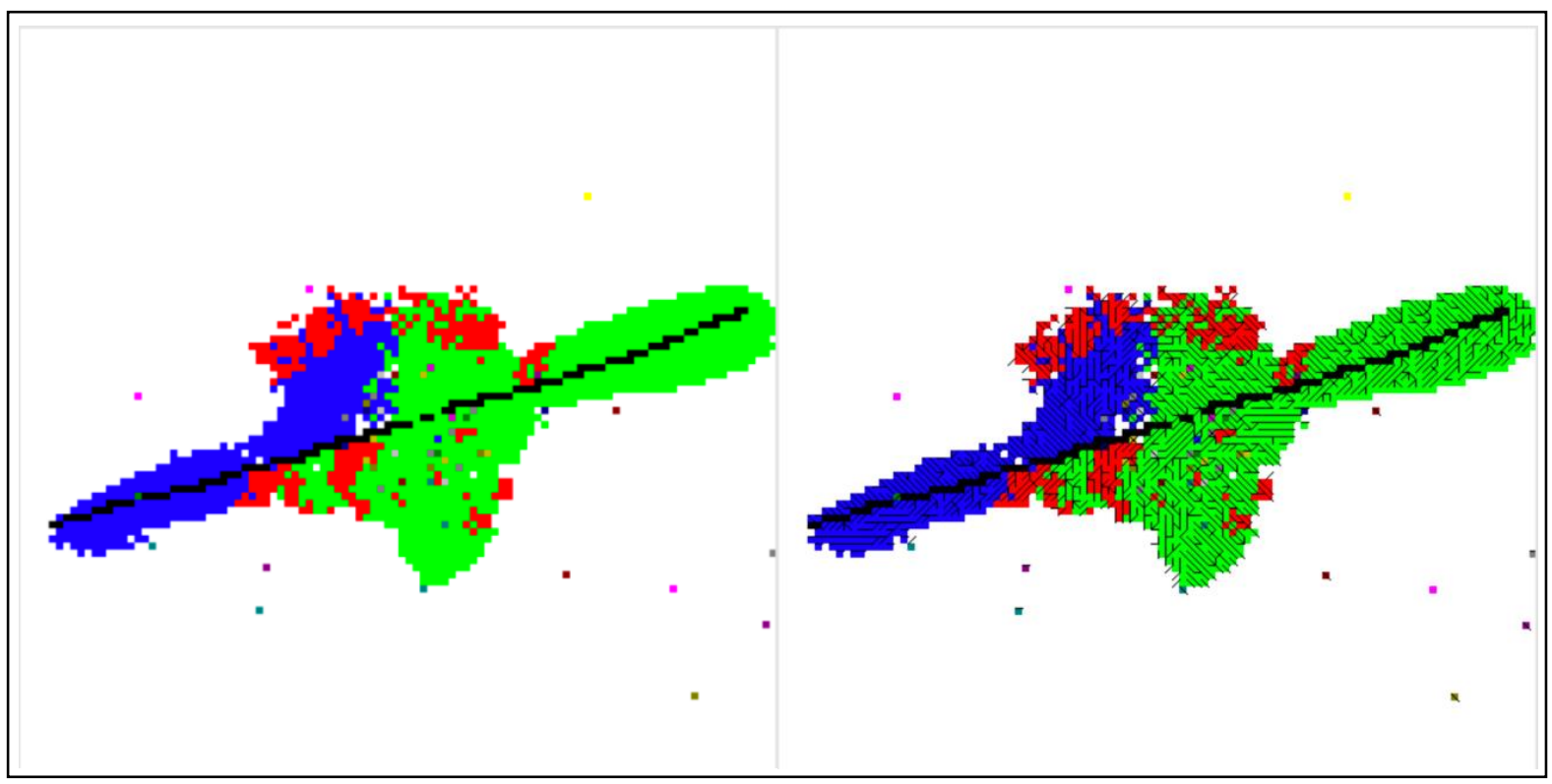

Figure 9: Spontaneous growth of small roads

outwards, the locally grown small roads will create an interconnected network towards the main roads, as shown in Figure 9.

\subsection{Discussion}

It is recognised that housing dynamics will significantly influence the development of urban environment, and that such dynamics may be lacking in some of the results presented in this article. Whilst there may be low intensity of housing-related processes in some of the outputs, this is only chance driven as result of random initialisation of the simulations shown in Figure 3 through to Figure 8 where residential cells were present but not dominant. However, in Figure 9, which also started as randomly initialised, it is the residential cells shown in green that have spread to become the most dominant and therefore engaging the full functionality of the housing processes in the model. The housing dynamics is built-in through residential cells being the source of labour and consumer processes and one of the key influencers on the demand in the property market, as shown in the diagram in Figure 2. The low intensity of housing related issues in some of the outputs of the model is therefore not a fundamental shortcoming of the model. In reality, some parts of city centres in the UK, such as Birmingham, do not have any residential use and, therefore, a model with no or low intensity of residential aspects should not be considered as unusual. 
We now focus on answering the research questions set in the introduction section of this article.

\section{Q1: What kind of urban data can be generated by a functional model?}

As it can be seen from the previous section, a cellular automata model can visualise a simulation of urban expansion over a number of years into the future. It can also visualise the propagation of attractiveness of certain urban features, such as roads or water and can result in the new development following the attractiveness gradient, as demonstrated by the road following shown in the previous section. A simple rule on an individual cell level that compares its attractiveness and density with the attractiveness and density of the neighbouring cells generates a secondary road in that cell and, as this is done in each cell, a network of secondary roads that lead towards a main road emerges.

Cells of the same type form clusters and the cellular automata model can provide information for cluster size frequency distribution analysis. The analysis after Equation (2) in the 'Results' section shows that cluster size frequency follows power law distribution in fine urban grain where there are gradual increases between cluster sizes. Urban developments that diverge from the gradual increases between cluster sizes are likely to change the character of the urban environment and gradually have a knock-on effect on the surrounding clusters. Inserting a very large development of a certain type into an existing fine grain distribution of land use types perturbs the balance and can lead to unintended consequences of certain urban actors disappearing.
As each land use type is characterised with energy consumption and carbon emissions, both can be tracked in the model through time. The same applies to the population metrics which changes dynamically as the urban area expands and different land use types become more dominant than others.

As the analysed model uses four different markets for exchange of products, retail goods, labour and property, market indices can be tracked and observed in response to the urban expansion. And, as the urban environment expands, the overall balance between different land use types will change and these changes can be easily summarised by the model.

\section{Q2: What could be the design implications of such data?}

Randomly generated urban data is unlikely to match an existing urban environment. However, when urban data is imported from a geographic information system (GIS), rasterised and subsequently mapped to match the model land use types, such a type of urban model can become of real value. Inserting investments into certain cells or groups of cells in the model can enable the running of what-if scenarios, so that urban designers could 'push and poke the model' and see what the consequences could be. As each time step of the model corresponds to a year, forward projections of the model will reveal different aspects of urban development and confirm whether any intended consequences will be achieved or whether there will be any unintended consequences. This application of the model would be similar in principle with making a business plan as it will enable the designer to try design interventions on 'paper' where actions can be undone before

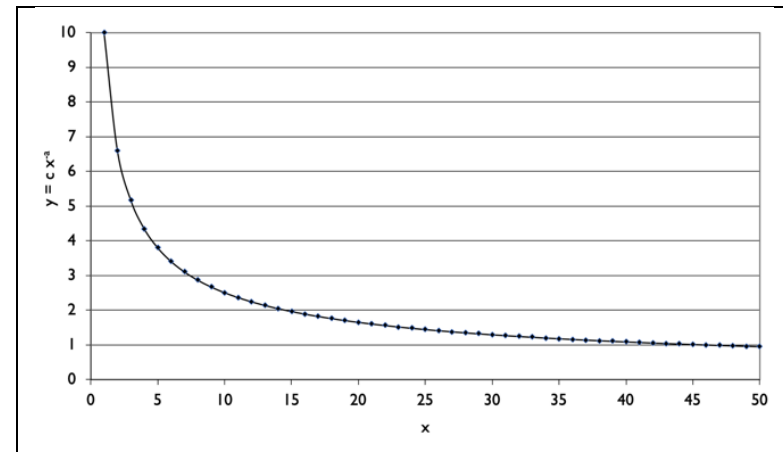

a) Normal plot

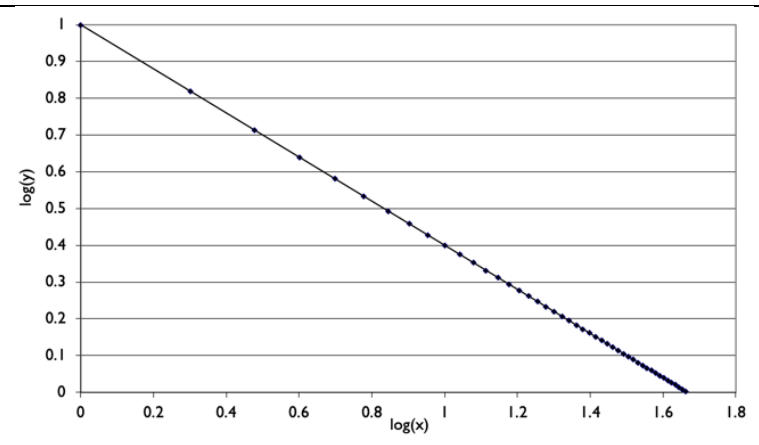

b) Log-log plot

Figure 10: Theoretical power law distribution 
committing significant resources to real development where decisions cannot be undone without considerable costs.

In Figure 3, we saw a timed simulation of urban expansion with ' $x$-ray' looking views of the attractiveness of cells and their carbon emissions, roads following as an emergent and unintended consequence of the model operation, and reaching the final pattern in Figure 4. Urban designers can use this approach to investigate the response to alternative urban interventions which can be inserted manually into the model at every time step.

In Figure 5, cluster size frequency was analysed and irregularities in the urban grain were observed in Figure 5b. In addition to a clear indication of a power law properties of the urban model, in which large clusters are rare and small clusters are frequent, the disruption of the continuity of the urban grain is what designers need to look for. Such disruptions will have a knock-on effect on the future development, potentially resulting in changing land use from one type to another and a large development gradually overtaking the land use types around it. Whilst observing the cluster size frequency analysis in Figure 5 , it is useful to compare it with its theoretical equivalent, shown in Figure 10. Although it is not possible to expect as smooth distribution in the urban grain of cluster sizes in Figure 5 as in its theoretical equivalent in Figure 10, the comparison between the two gives us an idea of the kind of regularity that can be expected, and that we need to look deeper into the reasons for irregularities if they occur.

In Figure 6a, we saw an acceleration, a decline and another acceleration in the population growth. What causes the population growth to accelerate and slow down? This is not easy to answer, but the method introduced here gives urban designers tools to play with and investigate. Similarly, in Figure $6 b$ and c, the product and service market indices decline rapidly, then go through a steady rise and start fluctuating towards the end of the simulation. Running what-if scenarios introduced by this method creates opportunities for urban designers to investigate different outcomes of urban interventions.

Energy consumption and carbon emissions levels can be tracked, as shown in Figure 7 and different interventions can be tried by designers. This is especially important as a number of cities in the UK, for instance, have declared climate emergency and the aspiration to become carbon-neutral by year 2030.

Summaries of land use types, such as shown in Figure 8 , can be used to quickly observe the changes of land use types over time. The cellular automata model can also assist designers with spontaneously growing secondary roads in new developments, as shown in Figure 9. With reference to Figure 9, it is worth noting that the model behaviour works consistently with Schelling's model of segregation (Schelling, 1971). Dynamic segregation principles driven by "discriminatory individual choices" (Schelling 1971) or, in other words, preferences towards the same cultural background, create the result of clustering and the emergence of neighbourhood patterns. It is possible to observe the Schelling principle in two respects with reference to Figure 9: first, cluster formation of the same cell types as the cells expand into their own types; and second, the preferences towards higher attractiveness give rise to the road following by the expanding cells.

Steps towards practical implementation of this method were made by developing GIS import/export functionality. This in itself created challenges, including the mapping of GIS land use types to the model land use types. Whilst it was intended to carry out the validation of the model on real GIS data, the funded period of the project lasting three years was too short for this to be achieved. However, all prerequisites for validation are built into the model, including placeholders for calibration factors, and therefore calibration will be carried out when suitable opportunities arise.

\subsection{Conclusions}

Urban environment is characterised with immense complexity yet it is essential to model it in order to test design interventions before significant financial investments are made for urban development. As we increasingly become aware of the implications of climate change, so that the UK, for instance, has legislated for cutting carbon emissions to zero by the year 2050 and some cities, such as Birmingham, have declared climate emergency and the aspiration to become carbon neutral by the year 2030, it is essential to have the tools capable of replicating and modelling the complexity of urban environment, in order to empower urban designers to make informed decisions. Whilst there are numerous tools that model certain aspects of urban growth, the method 
introduced in this article provides a comprehensive approach to modelling a range of urban environment processes, combining land use, movement of population, products and services, integrating with market economics. Although the article introduces simulations of randomly generated urban environment, importing GIS data mapping it to the land use types of the model, followed by calibration of the model using historic data, will empower designers with urban models of real value.

As already stated in the introduction, urban modelling is now over 50 -years old. In addition to a significant scope for a continuing theoretical research, the interdisciplinary characteristics of urban models give scope for practical applications in planning, and it is hoped that this article makes a contribution towards facilitating that objective.

\section{Acknowledgements}

The research introduced in this article is a follow up to a research project entitled CAST - City Analysis Simulation Tool, partially funded by European Commission Grant Agreement ID: EVK4-CT-200200079, and a Consortium of Participants: InteSys Itd, United Kingdom; Agencia Para Energia, Portugal; Camara Municipal de Oeiras, Portugal; Camara Municipal de Sintra, Portugal, Fit Consulting Srl, Italy; Municipality of Cholargos, Greece; Phaos Development of Energy and Environmental Systems Ltd, Greece; and University of Northumbria at Newcastle, United Kingdom.

\section{References}

Batty, Michael. 2007. Cities and Complexity: Understanding Cities with Cellular Automata, AgentBased Models, and Fractals. 1. paperback ed. Cambridge, Mass.: MIT Press.

Jankovic, Ljubomir. 2012. 'An Emergence-Based Approach to Designing'. The Design Journal 15 (3): 325-46.

https://doi.org/10.2752/175630612X133301866841 50.

Koutitas, G., N. Pavlidou, and L. Jankovic. 2010. 'A Comparative Study of Two Alternative Wildfire Models, with Applications to WSN Topology Control'. In FOREST FIRES 2010, 25-36. Kos, Greece. https://doi.org/10.2495/FIVA100031.
Langton, C. 1992. 'Life at the Edge of Chaos'. In Artificial Life II: Proceedings of the Workshop on Artificial Life: Held February 1990 in Santa Fe, New Mexico. Redwood City, Calif: Addison-Wesley.

Langton, Christopher G., ed. 1989. Artificial Life: The Proceedings of an Interdisciplinary Workshop on the Synthesis and Simulation of Living Systems, Held September, 1987, in Los Alamos, New Mexico. Santa Fe Institute Studies in the Sciences of Complexity, v. 6. Redwood City, Calif: Addison-Wesley Pub. Co., Advanced Book Program.

von Neumann, John. 1951. 'The General and Logical Theory of Automata.' In Cerebral Mechanisms in Behavior; the Hixon Symposium., 1-41. Oxford, England: Wiley.

- - . 1967. 'Theory of Self-Reproducing Automata. John von Neumann. Edited by Arthur W. Burks. University of Illinois Press, Urbana, 1966. 408 Pp., Illus. \$10'. Science 157 (3785): 180-180. https://doi.org/10.1126/science.157.3785.180.

Schelling, Thomas C. 1971. 'Dynamic Models of Segregation t'. The Journal of Mathematical Sociology 1 (2): 143-86. https://doi.org/10.1080/0022250X.1971.9989794.

Shannon, C. E. 1948. 'A Mathematical Theory of Communication'. Bell System Technical Journal 27 (3): 379-423. https://doi.org/10.1002/j.15387305.1948.tb01338.x.

Wilson, A.G. 1967. 'A Statistical Theory of Spatial Distribution Models'. Transportation Research 1 (3): 253-69. https://doi.org/10.1016/00411647(67)90035-4.

Wilson, Alan. 2018. 'The Future of Urban Modelling'. Applied Spatial Analysis and Policy 11 (4): 647-55. https://doi.org/10.1007/s12061-018-9258-6.

Wolfram, Stephen. 2002. A New Kind of Science. Wolfram Media. https://www.wolframscience.com. 